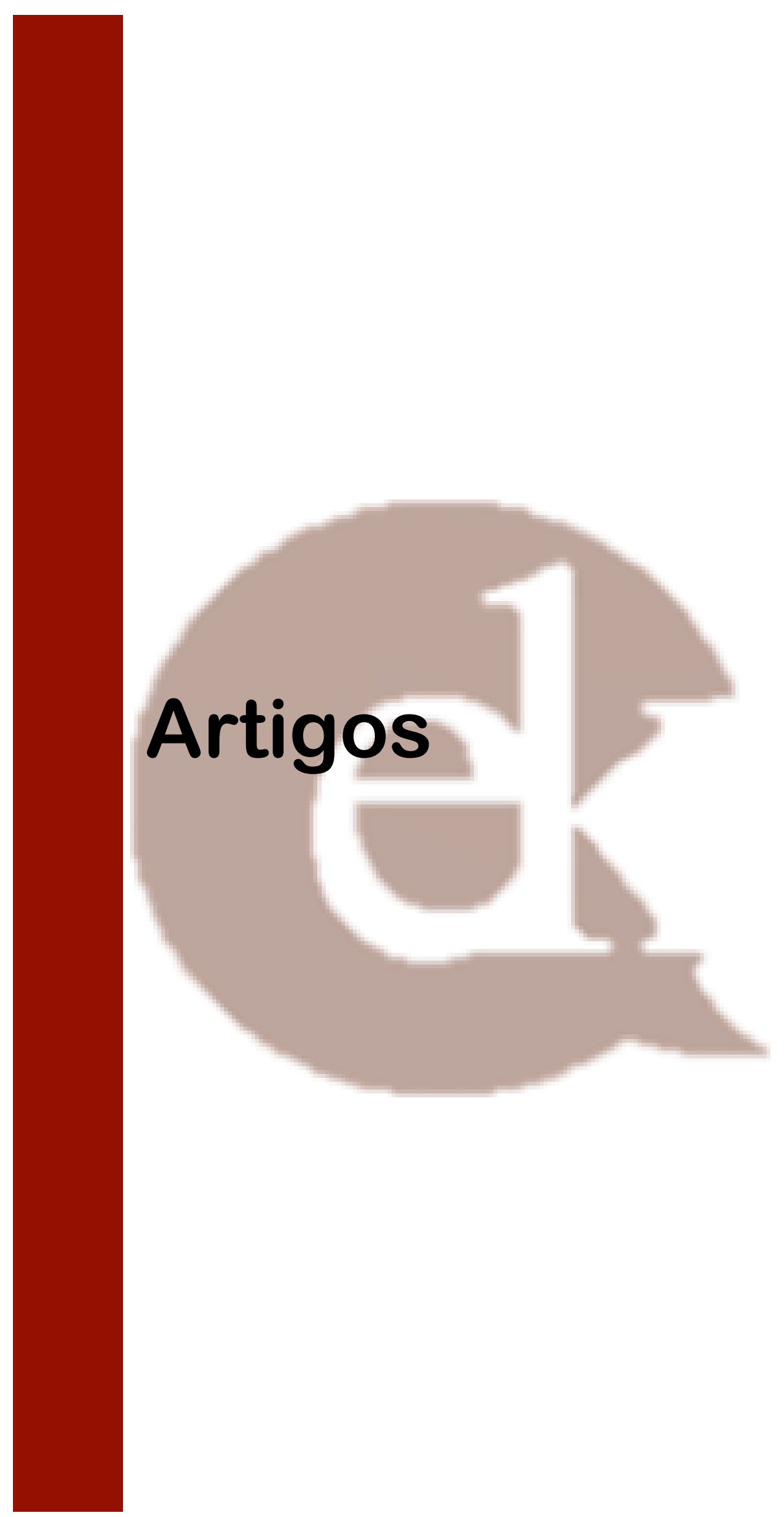




\title{
Johannes Lohmann - o Heidegger da ciência da linguagem?
}

\section{Johannes Lohmann - the Heidegger of language science?}

DOI: 10.12957/ek.2020.50029

\author{
Dr. Bernhard Josef Sylla \\ bernhard@ilch.uminho.pt \\ Universidade do Minho (Portugal)
}

\section{RESUMO}

A Johannes Lohmann (1895-1983), professor de linguística comparada e colega de Heidegger na Universidade de Friburgo, foi atribuído o epíteto "o Heidegger da ciência da linguagem". Nos estudos heideggerianos, são raros os trabalhos que consideram a influência heideggeriana sobre a obra de Lohmann. Uma das exceções é Kockelmans que, já em 1972, elogiou a obra de Lohmann e chegou à conclusão de que Lohmann compreendeu Heidegger corretamente. A análise aqui exposta não concorda com este juízo. Esta discordância é justificada através de uma leitura atenta de várias obras de Lohmann, que permite reavaliar a pretendida aplicação de algumas ideias fundamentais de Heidegger à Ciência da Linguagem, sobretudo as da diferença ontológica, da história do ser e da mundanidade. Chegar-se-á à conclusão que esta aplicação se afasta do pensamento de Heidegger, ou seja, que dificilmente se deixa conciliar com este.

\section{ABSTRACT}

Johannes Lohmann (1895-1983), professor of comparative linguistics and colleague of Heidegger at the University of Freiburg, was given the epithet "The Heidegger of language science". In Heideggerian studies, there are few works that consider the Heideggerian influence on Lohmann's work. One exception is Kockelmans who, already in 1972, praised Lohmann's work and came to the conclusion that Lohmann understood Heidegger correctly. The analysis presented here does not agree with this judgment. This disagreement is justified by a careful reading of Lohmann's various works, which allows us to reassess the intended application of some fundamental ideas of Heidegger to language science, especially those of ontological difference, the history of being and worldliness. It will be concluded that this application deviates from Heidegger's thinking and that is difficult, or rather impossible, to reconcile Lohmann's approach with that of Heidegger.

Palavras-chave: Heidegger. Lohmann. Recepção de Heidegger. Ciência da linguagem. Diferença ontológica.

Keywords: Heidegger. Lohmann. Heidegger studies. Language science. Ontological difference. 
1.

Foi Klaas Willems, professor de linguística geral da Universidade de Gent, que atribuiu o epíteto que consta do título - "o Heidegger da ciência da linguagem" - a Johannes Lohmann (WILLEMS, 1995, p. 27). Esse "Heidegger da ciência da linguagem" é pouco conhecido nos estudos filosóficos sobre Heidegger. Embora não seja difícil encontrar, aqui e ali, menções a Lohmann nos estudos sobre Heidegger, 1 certo é que estas menções se restringem, na maior parte das vezes, a breves alusões. A meu ver, são quase inexistentes as tentativas que procuram compreender a razão deste epíteto. A mais conhecida exceção é Kockelmans no seu já clássico On Heidegger and language (1972), onde o próprio Kockelmans, editor desta compilação de famosos artigos sobre o problema da linguagem em Heidegger, incluiu, traduziu e comentou o artigo de Lohmann, intitulado A diferença ontológica em Heidegger e a linguagem (1948). Com base neste artigo de Lohmann, que Kockelmans elogia como sendo "assaz notável" ("more than remarkable") (KOCKELMANS, 1972, p. 195), o autor chega à conclusão de que Lohmann compreendeu Heidegger corretamente e que abriu novas perspetivas para o entendimento da noção da diferença ontológica no que diz respeito ao seu entrelaçamento com a questão da linguagem.2

Não pretendo questionar o valor merecido da vasta obra de Lohmann. No entanto, argumentarei, com base numa leitura do já mencionado artigo de Lohmann e da sua obra principal, Philosophie und Sprachwissenschaft (1965), que oferece uma visão sinóptica das suas investigações e dos seus recursos a Heidegger, que a sua aplicação de ideias heideggerianas à ciência da linguagem se afasta do pensamento de Heidegger, ou seja, que dificilmente se deixa conciliar com este.

2.

Começarei com umas breves notas preliminares sobre o percurso académico de Johannes Lohmann (1895-1983). Doutorou-se em 1921, em Berlim, na área dos Estudos

\footnotetext{
1 A título de exemplo, cf. SMITH (1973, p. 175), GANE; SALE (2007, p. 327ss.), KITTLER (2003, p. 520).

2 "I am convinced that Lohmann is dealing with a very important aspect of Heidegger's philosophy, that he understands Heidegger correctly, and that (...) he has opened up a great number of unexpected and important perspectives" (KOCKELMANS, 1972, p. 200).
} 
Eslávicos, e obteve, ali, em 1930, a cátedra em linguística comparada. De 1933 a 1943, lecionou em várias universidades alemãs e suíças - Friburgo, Basileia e Rostock - antes de regressar definitivamente a Friburgo, onde ocupou a cátedra da linguística comparada até à sua aposentação em 1963. Devido ao seu entendimento das tarefas da linguística comparada, Lohmann dedicou-se, desde cedo, também a questões da linguística geral e da filosofia da linguagem. Esta abrangência dos seus estudos é testemunhada, de uma forma exemplar, na sua obra tardia Philosophie und Sprachwissenschaft, publicada em 1965.

Lohmann nutriu um profundo respeito, para não dizer admiração, pela obra e pessoa de Heidegger. Prova disto é ter assinado, juntamente com alguns colegas da Universidade de Friburgo, em 1950, um pedido de reintegração de Heidegger nesta universidade (HEIDEGGER, 2000, p. 807); ter dedicado o segundo volume da sua revista Lexis e a sua obra tardia já acima mencionada, Philosophie und Sprachwissenschaft, a Heidegger; ter sido um dos poucos participantes convidados do seminário de Heidegger e Fink sobre Heraclito3, em 1966/67. Mas a forma mais evidente da sua estima por Heidegger pautou-se pela sua tentativa de aproveitar a filosofia de Heidegger para os estudos da ciência geral e comparada da linguagem. No que se segue darei uma sinopse das teses nucleares de Lohmann e do seu recurso a Heidegger.

\section{3.}

Na sua dedicatória a Heidegger na edição do volume II, $\mathrm{n}^{\circ} 1$ da revista Lexis, de 1951, Lohmann apresenta ao leitor da revista o ponto fulcral da articulação do seu pensamento com o de Heidegger. Deste modo, a importante frase de Humboldt, que a

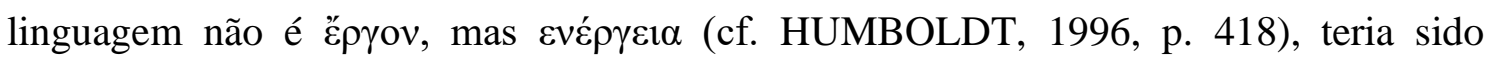
totalmente desconsiderada pela ciência da linguagem pós-humboldtiana. Somente o pensamento heideggeriano sobre a linguagem, nomeadamente a sua visão da linguagem como "casa do ser" e da historicidade deste ser, teria aberto o caminho para o entendimento da linguagem na sua verdadeira historicidade. Lohmann encerra a dedicatória ao esboçar a tarefa que convém à ciência da linguagem no seu diálogo com a filosofia:

3 Esta informação consta do posfácio de Friedrich-Wilhelm von Herrmann à edição do respetivo seminário (HERRMANN, 1986, p. 265). 


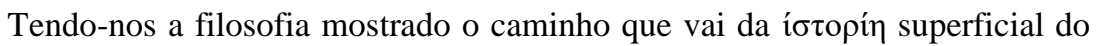
fato "linguagem" à sua verdadeira historicidade, assim podem as ciências "positivas" da linguagem retribuir à filosofia o seu serviço ao abrir-lhe, a partir do ponto de vista linguístico, o acesso aos horizontes históricos a partir dos quais o "ser" se revelou ao homem, para dispor sobre ele. As páginas seguintes, não obstante as imperfeições que inerem, naturalmente, a todas as primeiras tentativas, pretendem ser o início de uma tal "história do ser", empreendido por filósofos, filólogos e linguistas, num trabalho conjunto. (LOHMANN, 1951, p. 1).

As expectativas lohmannianas relativamente à colaboração entre filósofos, linguistas e filólogos apenas se concretizaram inicialmente, pois, a revista Lexis, mal inaugurada, acabou por não ser continuada a partir de 1954, ano que corresponderia à sua $4^{\mathrm{a}}$ edição.

Somente em 1965, após a sua reforma e mais de uma década de investigações mais ou menos solitárias, Lohmann apresentou, com o livro Philosophie und Sprachwissenschaft, uma sinopse deste seu projeto proclamado em 1951. É já no prefácio a este livro que se evidenciam as aspirações elevadas que Lohmann associava ao seu projeto, ao considerá-lo como uma viragem copernicana capaz de fundamentar um novo paradigma na ciência da linguagem. Ao mesmo tempo, o prefácio indica ainda um momento fundamental do entendimento lohmanniano da história da linguagem enquanto história do ser:

\begin{abstract}
O presente livro trata a questão principal do papel da linguagem na história do homem e para a forma do ser do homem (...). O seu verdadeiro objetivo é conduzir a uma espécie de "viragem copernicana" (no sentido kantiano), ao demonstrar que é imprescindível deixar de ver a linguagem da forma até agora habitual, i.e., como expressão do "pensamento" (no sentido de algo pensado e representado). Ao contrário e invertidamente, deve entender-se que o puro pensamento cartesiano nada mais é do que uma espécie de secreção que se foi formando paulatinamente ao longo do decurso da história humana (que desde o início foi história da linguagem), uma espécie de "resíduo" do natural falarum-com-o-outro; (...) (LOHMANN, 1965, p. 7).4
\end{abstract}

Esta tese de Lohmann apresenta fortes afinidades com a ideia cassireriana da gênese do logos através do desenvolvimento da linguagem, se bem que Lohmann nunca refira Cassirer. Tal como acontece em Cassirer (cf. 1997a; 1997b), as possibilidades lógicas do

\footnotetext{
4 Nesta citação, bem como em todas as citações seguintes, o uso de itálicos, maiúsculas, aspas, pontos de exclamação, etc., como meios diferentes de realce, corresponde ao respectivo texto original citado.
} 
pensamento desenvolvem-se inconscientemente no e pelo moroso processo do desenvolvimento da linguagem, e tal como em Cassirer, associa-se o rumo do desenvolvimento linguístico e cognitivo com a noção de um pensamento puro.

Também a suposta lei deste desenvolvimento é compatível com a teoria de Cassirer:

Postulamos aqui, em primeiro lugar, como lei principal desta história (...) que a história do homem, enquanto história da linguagem, constitui um processo no decurso do qual as categorias inicialmente muito concretas do falar entre os homens (...) se vieram a purificar, em determinados locais da Terra, em categorias "puras". Estas categorias, no entanto, ainda persistiram num estado inconsciente. Somente a partir de um certo nível de purificação e quando as condições sociais lhes eram favoráveis, tencionaram a tornar-se, como que por “eclosão repentina”, conscientes e capazes de produzir, neste nível do pensamento consciente, novas formas espirituais. (LOHMANN, 1965, p. 49).

De forma semelhante a Cassirer, Lohmann postula, portanto, que a faculdade de reflexão e objetivação não apenas aumenta ao longo do desenvolvimento linguístico, mas que, em determinados pontos fulcrais deste desenvolvimento, adquire um nível qualitativamente distinto, não alcançável por mera acumulação, resultando assim em formas superiores de pensamento e consciência. A alusão a Descartes, na passagem acima citada, não é aleatória, mas antes um indício muito forte de que, ao contrário de Heidegger, Lohmann precisa do momento da consciência como momento chave da sua teoria. A citação seguinte evidencia isto claramente:

\begin{abstract}
A linguagem é - dito de uma forma paradoxal, mas não, por isso, menos exata - a "consciência (individualmente ainda) inconsciente" da humanidade, a partir da qual, num longo processo de secreção, surge a "consciência consciente", mas de tal forma que este processo, ainda hoje, de modo algum terminou (também estas minhas considerações devem ser entendidas como uma etapa - e nem sequer a última! - no caminho do "vir-a-si-mesmo" da "consciência em si", que se desenvolve no falar-um-com-o-outro e que existe, primeiro, apenas facticamente, não se sabendo ainda a si mesmo). (LOHMANN, 1965, p. 62). 5
\end{abstract}

\footnotetext{
5 As afinidades com a filosofia de Hegel parecem aqui ser óbvias. Uma referência curta a Hegel, imediatamente a seguir ao trecho citado, deixa claro que Lohmann não rejeitaria categoricamente esta afinidade, caso o autoconhecimento da consciência fosse concebido como um processo de desenvolvimento espiritual na linguagem.
} 
Como é que Lohmann estabelece, a partir deste fundamento teórico, a ponte com a "história do ser" de Heidegger? Esta surge, no decurso deste seu livro, apenas na parte mais avançada do texto:

Resulta daí [do saber que a consciência se forma a partir da linguagem], para a lógica semântica, o princípio fundamental acima mencionado que esta não deve partir da ideia da existência de uma realidade em si (cujo reflexo fosse a consciência (...)), mas antes da praxis da articulação fonética da linguagem (como solo matricial de todos os outros sistemas de expressão). É aí que residiria a viragem copernicana efetivamente realizada, no decurso da qual (...) a consciência individual, tornada consciente de si mesma, é afastada do centro da história da consciência (sendo essa, interpretada analogamente, a "história do ser" heideggeriana)! (LOHMANN, 1965, p. 158).

Lohmann julga, pois, fazer jus a Heidegger ao postular que a sua teoria sobre a gênese da consciência ao longo da história da linguagem, devido à dependência fundamental da consciência da linguagem, permite (i) distanciar-se do paradigma cartesiano da representação do objeto de uma realidade extensional pelo sujeito pensante; (ii) concebendo este sujeito, no seu verdadeiro ser, não como consciência individual, mas, antes, como consciência linguística coletiva e supraindividual; e (iii) identificando esta consciência coletiva e supraindividual com o "ser" em Heidegger. A meu ver, Heidegger jamais poderia concordar com esta interpretação. Para ele, a concentração na consciência enquanto capacidade de reflexão que se vai formando paulatinamente na história do desenvolvimento humano nunca pode ser o motor da história do ser. Antes pelo contrário, esta consciência é uma das caraterísticas nucleares de uma das fases da "história da metafísica" que Heidegger associa a Descartes e a Kant e que provoca um agravamento do esquecimento do ser. Para além disso, parece-me que a questão da distinção entre linguagem apropriada e inapropriada, uma preocupação decisiva em Heidegger na sua filosofia após a Kehre, não tem lugar na teoria de Lohmann.

\section{4.}

Até aqui consideramos apenas as premissas fundamentais da teoria de Lohmann. Tendo em conta o desenvolvimento mais específico desta teoria, anotamos dois momentos fundamentais, um dos quais recorre a Heidegger.

O primeiro momento tem um caráter predominantemente metódico. Segundo Lohmann, a investigação linguística do desenvolvimento da linguagem ao longo da 
história deve concentrar-se nas formas decisivas da constituição da consciência e da realidade, que ocorreram neste processo. Apenas depararíamos com estas formas decisivas se deixássemos de investigar línguas particulares isoladamente e começássemos a considerar tipos de línguas. Mas também não seria suficiente investigar apenas alguns tipos de línguas, antes deveriam ser considerados todos os tipos, porque apenas podemos saber quais as diferenças específicas entre os respetivos tipos se o lugar e a especificidade de cada tipo for tido em conta. Só assim uma linguística comparada se tornaria universal e merecedora do epíteto "panlinguística" (LOHMANN, 1965, p. 59).

Este primeiro momento encontrará a sua principal justificação no segundo momento que diz respeito às diferenças entre os tipos de línguas. Lohmann realça duas especificidades tipológicas como catalisadores decisivos do processo da formação da consciência. Lohmann encontra a primeira especificidade em três tipos de línguas que se situam geograficamente num eixo norte-sul, a saber, o tipo das línguas indo-germânicas, o das línguas hamito-semitas e o das línguas bantu. Ao contrário dos restantes 6 três tipos de línguas uralo-altaicas, de línguas indo-chinesas e de línguas malaio-polinésias, que constituem uma tríade geograficamente situada num segundo eixo norte-sul, paralelo ao primeiro, somente a primeira tríade terá desenvolvido a especificidade de distinguir entre um núcleo conceptual - a raiz da palavra, que, segundo Lohmann, representa e "encarna" o "ser" não relacionado e não "contextualizado" -, e todos os meios morfológicos, sobretudo todo o tipo de flexões, cuja função é estabelecer a relação com o "ente", ou seja, com a respetiva situação concreta referida no ato de fala. No seu livro de 1965, Philosophie und Sprachwissenschaft, a análise desta distinção ocupa um terço do texto, ou seja, cerca de cem páginas (ibid., p. 136-235). A tese de que esta caraterística tipológica das línguas manifesta uma "diferença ontológica" foi, no entanto, apresentada já em 1948 (LOHMANN, 1948, p. 69), no artigo que Kockelmans, na sua obra acima referida, traduziu e comentou. Também se encontra, neste artigo de 1948, a segunda tese relacionada com esta especificidade, segundo a qual apenas um dos três tipos da primeira tríade, o tipo das línguas indo-germânicas, terá desenvolvido a predicação com a cópula,

\footnotetext{
6 Lohmann não considera as línguas (meso-)americanas de uma forma sistemática. Nos gráficos apresentados, no artigo de 1948, estas parecem-se com um apêndice desnecessário e incómodo que perturba o equilíbrio entre as duas tríades dos seis tipos de línguas que, segundo Lohmann, são as fundamentais (cf. LOHMANN, 1948, p. 91).
} 
i.e., o seu uso nos juízos, o que teria levado à representação linguística da diferença ontológica7 e, daí, à sua manifestação concreta. Lohmann sublinha repetidamente que só e somente através do uso da cópula e do exercício deste ao longo de séculos, se chegou à separação consciente das estruturas sintáticas e do par signifiant - signifié (LOHMANN, 1965, p. 98) do sujeito falante, ou seja, que se chegou à colocação do objeto da fala e do nexo das relações estabelecidas na fala à frente do sujeito. O sujeito torna-se, assim, consciente não apenas de que "algo" está colocado à sua frente, mas também do caráter relacional deste algo. Esta relação inclui o sujeito, pois é este que entende que está a tomar uma posição quando enuncia um juízo e que é responsável pela articulação sintático-semântica desta relação. É, portanto, através do uso da cópula que se junta à primeira dimensão da diferença ontológica - que consiste na aplicação do ser ao ente, através da flexão e integração de elementos linguísticos básicos, como raízes e radicais, em unidades linguísticas morfologicamente mais complexas - uma segunda dimensão, pela e na qual o sujeito se torna definitiva e plenamente consciente desta diferença ontológica $e$ de si mesmo (cf. ibid., p. 105ss.) enquanto instância relacionada com a esfera objetual, não obstante esta última possuir, por si mesma, também um caráter relacional.

O entendimento lohmanniano do conceito de "diferença ontológica" apresenta, assim, duas caraterísticas: por um lado, há uma dupla dimensão do que se entende por "ser" - "ser" enquanto raiz inflexionada de palavras, e "ser" como estado de desenvolvimento da consciência. Por outro lado, é no tipo de consciência onde a diferença ontológica se manifesta. A consciência mais desenvolvida, através da qual a diferença ontológica se desencobre, é a consciência do sujeito que toma plena posse da sua própria capacidade de juízo e que habilita o sujeito a distinguir clara e distintamente entre sujeito e objeto.

Consequentemente, Lohmann não esconde a sua pretensão de "fusionar" Heidegger e Kant:

"Diferença ontológica" (Heidegger) (...) e "unidade sintética de apreensão" (Kant, Crítica da Razão Pura, B 134, nota de rodapé) são apenas nomes

\footnotetext{
7 Quanto ao desenvolvimento desta tese, confira-se o artigo de Lohmann de 1948 (LOHMANN, 1948, p. 69), onde a diferença ontológica é associada exclusivamente às línguas indo-germânicas. No livro de 1965, Lohmann carateriza todos os três tipos da primeira tríade como tipos da "diferença ontológica", se bem que, também aqui, seja apenas o indo-germânico onde esta diferença encontra o seu desenvolvimento pleno, porque permite a objetivação da própria diferença ontológica enquanto diferença.
} 
diferentes para o "ponto mais alto" (Kant, op. cit.) ao qual o pensamento humano pode chegar - i.e., ELE MESMO, tendo-se tornado transparente para si mesmo. Ora, este sistema dos 6 "grandes tipos", enquanto um todo, que a tipologia das línguas de Humboldt tinha descoberto sem o saber explicitamente (!), é direcionado e predestinado para este estádio final. E, no fundo, tanto a totalidade dos aspetos singulares deste grande "organismo", bem como o sistema em si como um todo, são igualmente maravilhosos. (LOHMANN, 1965, p. 145).

As nossas análises até aqui apresentadas mostram, por um lado, que há surpreendentes afinidades com a perspectiva teórica de Cassirer - referimo-nos sobretudo aos volumes I e III da sua Filosofia das formas simbólicas (CASSIRER 1997a; 1997b) - segundo a qual a lógica do desenvolvimento das línguas e da linguagem enquanto capacidade humana resultam numa gênese do logos puro, embora Lohmann siga caminhos e metodologias diferentes, uma vez que confere exclusivamente ao uso da cópula e à formação da consciência do eu a função catalisadora da gênese deste logos puro. Também a conceção deste logos puro se distancia de Cassirer, pois é nesta questão que Lohmann pretende aproximar-se de Heidegger, i.e., este logos é, por um lado, o surgimento da consciência que se torna plena consciência e, por outro lado, a manifestação da diferença ontológica e, com ela, a manifestação do ser em distinção ao ente. Interpretar, no entanto, a diferença ontológica como capacidade evoluída de reflexão e juízo, graças à qual a distinção entre sujeito e objeto se torna clara e distinta, não pode, a meu ver, merecer o consentimento de Heidegger.

\section{5.}

A primazia da função do uso da cópula como sinal do surgimento de um novo estágio da transparência da consciência e como manifestação da diferença ontológica e do ser, é associada por Lohmann, na maior parte das suas argumentações, ao Heidegger tardio, ou seja, à sua ideia da história do ser. Contrariamente a Heidegger, esta história não é decadente, no sentido de um crescente esquecimento do ser.8 Em Lohmann, o ser, inicialmente em estado não evoluído, potencial, latente, começa a manifestar-se e

8 KOCKELMANS (1972, p. 204) é da opinião de que o momento do esquecimento do ser não falta em Lohmann pela simples razão de que, segundo a perspectiva de Lohmann, os falantes das línguas indogermânicas se teriam esquecido do verdadeiro valor desta diferença ontológica. A obra de Lohmann, neste sentido, teria uma função "iluminista" em prol da verdadeira dignificação de algo que já aconteceu, mas cujo impacto não foi avaliado e estimado adequadamente. 
desencobrir-se paulatinamente, sem que haja uma ameaça para o seu desenvolvimento. Por outro lado, Lohmann não se restringe a associar a sua teoria ao Heidegger tardio, mas julga haver também afinidades com o primeiro Heidegger de Ser e tempo. Mas, mais uma vez, é através do uso da cópula que, assim Lohmann, se revela esta afinidade.

Referindo-se à noção de Zwischenwelt, "mundo intermédio" entre sujeito e objeto, que Humboldt tinha usado para se referir ao contributo da linguagem no trabalho do conhecimento do mundo, contributo esse que, por seu lado, molda e constrói o próprio mundo (cf. HUMBOLDT, 1996, p. 19ss.), Lohmann afirma que este mundo intermédio apenas surge conscientemente com o uso da cópula. Em línguas onde este uso não existe, não haveria, stricto sensu, nenhuma Zwischenwelt, porque, no fundo, este mundo moldado pela linguagem seria, para o falante que vive nestas línguas sem cópula, "o próprio mundo" (LOHMANN, 1965, p. 98). Apenas quando se alcança o uso da cópula, pode o mundo tornar-se objeto, e somente assim, o estatuto do mundo pode tornar-se questionável, i.e., pode tornar-se algo que experienciamos como diferente de nós ou, como diz Lohmann, em

(...) "ilusão", ou, dito melhor, em "ficção" que simultaneamente é condição da possibilidade do ser-aí humano enquanto "ser-no-mundo" (de nada diferente da autoconsciência transcendental em Kant - o "Eu penso" que deve acompanhar todas as minhas representações -, que é a condição da possibilidade de toda a experiência). (LOHMANN, 1965, p. 105ss.)

Como esta passagem bem documenta, o estar/ser-no-mundo do ser humano que tem, desde sempre, um caráter imediato, torna-se, numa determinada fase do desenvolvimento das línguas do tipo indo-germânico, num estar/ser-no-mundo mediato, onde a distância entre sujeito e objeto se torna apreensível pela reflexão consciente, e somente assim o "entre" - ou seja, a diferença ontológica enquanto Zwischenwelt - pode sair do estado latente e revelar-se na plena "ilatescência” (“Illatescenz”) (LOHMANN, 1965, p. 108). Esta interpretação que "transplanta" a análise heideggeriana da mundanidade, em Ser $e$ tempo, para o desenvolvimento linguístico humano, acaba evidentemente por distinguir o modo da Vorhandenheit com o selo de excelência, em detrimento do modo da Zuhandenheit, invertendo assim o estatuto de primordialidade que Heidegger confere ao modo da Zuhandenheit. Conferir ao alcance de um maior grau de reflexão e de consciência o estatuto de caraterística ontologicamente decisiva parece-me distorcer a 
filosofia heideggeriana, tanto a de Ser e tempo como a da pós-Kehre, ao voltar aos paradigmas do idealismo alemão que conferiam à autoconsciência do homem e à consciência em geral a maior dignidade.

6.

Não é do meu conhecimento que Heidegger se tenha pronunciado publicamente sobre o recurso de Lohmann às suas obras e sobre a teoria de Lohmann em geral. Creio que Heidegger se absteve deliberadamente de comentários publicamente pronunciados, não apenas porque Lohmann se empenhou publicamente a favor de Heidegger, na fase problemática (para Heidegger) do pós-guerra, mas também porque Lohmann não escondeu a sua admiração e grande estima pelo colega. Nestas circunstâncias, Heidegger costumava mostrar grande abertura e "tolerância" para com posicionamentos filosóficos e científicos diferentes, mesmo quando estes se afastavam bastante das suas convicções. Para além disso, é óbvio que ambos tiveram ocasiões mais que suficientes para o diálogo e a conversa, pois moravam na mesma cidade e ensinavam na mesma universidade. Contudo, o silêncio público de Heidegger perante as interpretações de Lohmann não alteram, a meu ver, nada no que respeita ao diagnóstico aqui apresentado, que defende que o entendimento lohmanniano de "diferença ontológica" e de "ser" não são compatíveis com o entendimento de Heidegger, situando-se, antes, no âmbito da perspectiva heideggeriana sobre o pensamento da história da metafísica.

\section{Referências bibliográficas}

CASSIRER, E. Philosophie der symbolischen Formen. Erster Teil: Die Sprache. Darmstadt: Primus, 1997a. Philosophie der symbolischen Formen. Dritter Teil: Phänomenologie der

Erkenntnis. Darmstadt: Primus, 1997b. 
GANE, N.; SALE, S. Interview with Friedrich Kittler and Mark Hansen. Theory, Culture \& Society, 24 (7-8), pp. 323-329, 2007.

HEIDEGGER, M. Seminare (ed. Curd Ochwadt). Frankfurt/Main: Klostermann, 1986 [GA 15].

Reden und andere Zeugnisse eines Lebenswegs (ed. Hermann Heidegger).

Frankfurt/Main: Klostermann, 2000 [GA 16].

HERRMANN, F.-W. v., Nachwort von Friedrich-Wilhelm von Herrmann. In: HEIDEGGER, M., Seminare, pp. 265-266. Frankfurt/Main: Klostermann, 1986.

HUMBOLDT, W. v., Werke in fünf Bänden, Bd. III: Schriften zur Sprachphilosophie (ed. Andreas Flitner \& Klaus Giel, $8^{\text {a }}$ ed.). Darmstadt: Wissenschaftliche Buchgesellschaft, 1996.

KITTLER, F., Medien- und Technikgeschichte. Oder: Heidegger vor uns. In: THOMÄ, D. (ed.), Heidegger-Handbuch. Leben - Werk - Wirkung, pp. 520-523. Stuttgart \& Weimar: Metzler, 2003.

KOCKELMANS, J. J. (ed.). On Heidegger and Language. Evanston: Northwestern University Press, 1972.

LOHMANN, J. Martin Heideggers ontologische Differenz und die Sprache. Lexis, Bd. I, pp. 49-106, 1948.

Widmung. Lexis, Bd. II, 1, 1951.

. Philosophie und Sprachwissenschaft. Berlin: Duncker \& Humblot, 1965.

SMITH, F. J. Two Heideggerian Analyses. In: BALLARD, E. \& SCOTT, C. E. (eds.), Martin Heidegger: In Europe and America, pp. 171-182. The Hague: Nijhoff, 1973.

WILLEMS, K. Sprache und Sprachgemeinschaft. Überlegungen zu den Voraussetzungen des 'Sprachapriori' in Linguistik und Philosophie. Indogermanische Forschungen, 100, pp. 1-76, 1995.

Recebido em: 10/04/2020 | Aprovado em: 15/04/2020

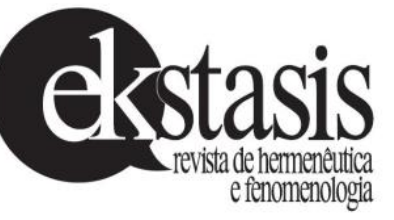

